\title{
Do cordel à midiatização: a pesquisa de Antônio Fausto Neto
}

\author{
Juliana de Amorim Rosas'
}

\section{Resumo}

Este texto faz um apanhado histórico e cronológico da obra do pesquisador de comunicação e jornalismo, Antônio Fausto Neto. Cita suas principais obras, sua colaboração e produções com a Associação Nacional dos Programas de Pósgraduação em Comunicação (Compós), da qual foi um dos fundadores, bem como faz uma síntese de suas atuais pesquisas, envolvendo jornalismo, midiatização e o ofício do jornalista.

Palavras-chave: Antônio Fausto Neto. Pesquisa. Comunicação. Jornalismo.

\section{Abstract}

This text makes a historical and chronological resumé of the work of Antônio Fausto Neto - communication and journalism researcher. It brings his main works, his collaboration and productions with the Brazilian National Association of Postgraduate Programs in Communication (Associação Nacional dos Programas de Pós-graduação em Comunicação - Compós), of which he was one of the founders, as well as a synthesis of his current research, involving journalism, mediatization and the journalist's craft.

Keywords: Antônio Fausto Neto. Research. Communication. Journalism.

\footnotetext{
I Doutoranda no Programa de Pós-graduação em Jornalismo da Universidade Federal de Santa Catarina. Mestre em Comunicação pelo Programa de Pós-graduação em Comunicação da Universidade Federal do Paraná, possui graduação em Comunicação Social - Jornalismo, pela Universidade Federal da Paraíba e especialização em Sociologia. Atua profissionalmente na área de comunicação, jornalismo e assessoria de imprensa. Email: rosasjuliana@yahoo.com.br
}

Revista Pauta Geral-Estudos em Jornalismo, Ponta Grossa v.5, n.2, p. 132-146, Jul/Dez 2018. 


\section{Introdução}

Antônio Fausto Neto, jornalista, comunicólogo, analista do discurso, pesquisador professor universitário, nordestino, brasileiro, cidadão do mundo. Diversos títulos, produções bibliográficas e características definem este autor da área jornalística e das ciências da comunicação. Suas contribuições perpassam a semiótica, a análise do discurso, televisão, rádio e jornalismo. Para este último, deu grandes contribuições mesmo em parceria com outros temas e ciências; ajudou a construir cursos de graduação e pós-graduação no país na área jornalística e até hoje segue produtivo.

Pelos seus estudos e contribuições mundo afora, Fausto Neto parece um cidadão do mundo, mas é, sobretudo, um exemplar pesquisador deste vasto Brasil, tendo sido professor efetivo ou visitante de inúmeras universidades brasileiras, em diversos estados. Nordestino hoje radicado na Região Sul, ajudou a criar o curso de Comunicação Social na Universidade Federal da Paraíba (UFPB); o primeiro mestrado profissional em jornalismo do país, nesta mesma universidade; e o primeiro curso de Doutorado em Comunicação do sul do país, na instituição onde hoje atua, a Universidade do Vale do Rio dos Sinos (Unisinos). Nascido em Fortaleza - CE, em 1947, lá iniciou sua carreira jornalística. Graduou-se em Jornalismo pela Universidade Federal de Juiz de Fora, estado de Minas Gerais, em 1972; obteve título de mestre em Comunicação pela Universidade de Brasília, em 1977, fez doutorado em Sciences de La Comunication et de L'information na Ecole des Hautes Etudes en Sciences Sociales, na França, em 1982; e estudos de pósdoutorado na Universidade Federal do Rio de Janeiro (UFRJ), em 1990.

Trinta e seis anos após ajudar a formar o curso de graduação em Comunicação Social da UFPB, volta a esta mesma instituição, em 2013, para receber o título de Doutor Honoris Causa, a honraria mais importante da universidade. Fausto Neto também ajudou a criar a Associação Nacional dos Programas de Pós-graduação em Comunicação (Compós), fundada em 16 junho de 1991. Desta associação foi vice-diretor e secretário geral, tendo produzido e organizado diversos livros, resultados dos encontros anuais.

\section{Produção de livros}


A produção acadêmica de Antônio Fausto Neto é vasta. Por este motivo, enumeraremos sua bibliografia cronologicamente, sempre que possível, destacando seus principais trabalhos. Sua dissertação de mestrado resultou em seu primeiro livro, Cordel e a ideologia da punição (1979). Baseado na interdisciplinaridade das ciências humanas, neste trabalho, o autor busca um quadro teórico-metodológico para a constituição de um determinado sistema de leitura dos textos da literatura de cordel.

A reflexão se desenvolve num plano que discute a problemática da ideologia na produção simbólica, destacando sua pertinência para as análises das práticas de comunicação; sistematiza uma revisão da literatura metodológica sobre o trabalho de análise de textos e elabora uma crítica das principais metodologias de leitura do cordel, contrapondo-as a uma proposição que apresenta a literatura de cordel como uma prática cultural com características de dominação simbólica.

O autor realiza esta proposição através de um trabalho com textos que apresentam determinadas estratégias de sobrevivência de grupos subordinados simbolicamente pela ideologia dominante. Tal ideologia, atuando pelo trabalho da linguagem, intervém no próprio processo de produção e organização das mensagens destes grupos, definindo e estabelecendo pautas e códigos normativos, pelos quais os dominados são ensinados a serem subalternos.

A literatura de cordel, que se popularizou no Nordeste brasileiro, data de séculos atrás, da época do Renascimento, com a impressão de relatos originalmente transmitidos oralmente pelos trovadores medievais. Nos dias de hoje, o cordel é muitas vezes visto como transmissor de "causos" jocosos, porém, vê-se que o pesquisador foi mais além nesta forma de literatura, revelando o lado da dominação ideológico-discursiva.

O segundo livro do pesquisador é O corpo falado - a doença e morte de Tancredo Neves nas revistas semanais brasileiras, de 1988. Aqui podemos ver a pesquisa de Antônio Fausto Neto mais focada no jornalismo. A análise de como pessoas conhecidas (políticos, celebridades, ou os chamados "olimpianos") são retratadas na mídia, em especial a doença e morte destas é uma temática que acompanhará o autor ainda em várias pesquisas, como no caso da morte do cantor Cazuza até mesmo nos dias atuais, com o retrato das enfermidades dos ex-presidentes Lula da Silva e Dilma Rousseff. Nas produções da época, o pesquisador focou em questões que envolviam a metodologia do Revista Pauta Geral-Estudos em Jornalismo, Ponta Grossa v.5, n.2, p. 132-146, Jul/Dez 2018. 
discurso informativo. Alguns títulos de capítulos e subcapítulos de O corpo falado dão a ideia da análise focada na linguagem jornalística realizada por Fausto Neto, a exemplo de: 1 O Processo de Hierarquização do Fato; 1.1 Uma Pluralidade de Acontecimentos; 1.2 Fotos: Decoração, Evocação ou Fragmento do Real?; 2 Gênese do Acontecimento; 2.1 Jornalista, o Ubíquo Escutador; 4.1 O Problema da Administração da Informação; 4.2 Jornalistas: Árbitros ou Relatadores?; 50 "Desrecalcamento" dos Jornalistas; 5.1 As Condições de Trabalho dos Jornalistas.

Seguindo a temática mencionada em parágrafo anterior, em 1991, o autor lança Mortes em derrapagem: os casos Cazuza e Corona no discurso da comunicação em massa. O texto foi escrito para atender às exigências de um programa de estudos de pósdoutoramento realizado em 1989, na Escola de Comunicação da UFRJ. O objeto da análise foi inicialmente material jornalístico produzido naquele ano pelas revistas especializadas sobre a doença e morte do ator Lauro Corona e do cantor Cazuza, bem como a cobertura que alguns jornais brasileiros fizeram sobre o caso no dia da morte dos artistas. Este é mais um livro focado na análise jornalística e questões discursivas, como podemos ver mais nitidamente pelos títulos de algumas partes e capítulos da obra: Introdução - acerca da questão da morte dos olimpianos na comunicação de massa; Jornalismo: Classificação e Produção do Real; Conclusões - a morte é uma questão discursiva.

Comunicação e mídia impressa - estudos sobre a Aids (1999) é o livro seguinte, mais uma vez, focado no jornalismo. Traz outras temáticas abordadas anteriormente (morte, doença e a Aids, em especial), porém, sem focar nos "olimpianos". Aqui, Antônio Fausto Neto apresenta um exemplo de análise de discurso dirigida para a construção de sentido da mencionada doença nos principais jornais do país. Nesse momento, após (enquanto docente) ter passado por respeitadas instituições de ensino como Pontifícia Universidade Católica de Minas Gerais (PUC-MG); Universidade de Brasília (UnB) e UFPB, o autor já se encontrava na universidade em que permanece até hoje, a Unisinos, localizada na cidade de São Leopoldo, Região Metropolitana de Porto Alegre, Rio Grande do Sul.

No livro, Fausto Neto mostra como, desde o surgimento da Aids, os jornais trataram de anunciá-la, gerando estratégias de produção e de efeito de sentidos a partir 
das falas de médicos, religiosos e leitores comuns. O estudo faz um levantamento detalhado de tudo o que se falou sobre a doença nos grandes jornais do país, expondo um modelo de pesquisa em que a linguagem não se constitui exclusivamente em instância de inteligibilidade social, mas em dispositivo de atualização das relações de força na sociedade. Entre os capítulos que enfocam a questão jornalística estão: A Aids e a Mídia Impressa; Os Modelos de Anunciabilidade; Entre o Público e o Privado.

Podemos perceber que, mesmo o início de sua trajetória acadêmica e de pesquisa estando focado nas questões discursivas, Fausto Neto tinha como marca o empírico; e este empírico era o jornalismo e o objeto jornalístico. Sua análise dos discursos e ideologias não eram somente teóricas. Fausto Neto nunca se apresentou como linguista ou teórico da linguagem. Sempre se identificou como um jornalista e um acadêmico com formação jornalística que se utiliza de arcabouços teórico-linguísticos para análises de temas midiáticos.

Suas análises evoluíram, tornaram-se abrangentes, agregaram-se. Ou seja, Fausto Neto não se tornou um pesquisador de "períodos", daqueles que tiveram como objeto certas temáticas posteriormente abandonadas. Alguns temas em sua longa carreira retomam sob outras perspectivas, revistas, novamente analisadas, com outros focos, repaginadas e não datadas. São casos de temas como o cordel, doenças, morte, Aids, análises políticas, midiáticas e de representantes do poder executivo.

Por estar na diretoria da Compós, seja como fundador, vice-presidente (19931995) ou secretário geral (1999-2001), uma parte considerável da produção bibliográfica de Antônio Fausto Neto provém de livros organizados pela Compós. Em vários livros, ele está, em sua maioria, entre os organizadores, mas igualmente como autor de capítulos. Como organizador em livros da Compós, Fausto Neto aparece em: Comunicação e Cultura Contemporâneas (I COMPÓS, 1993); Brasil: Comunicação Cultura \& Política (II COMPÓS, 1994); A encenação dos sentidos - mídia cultura e política (III COMPÓS, 1995); O Indivíduo e as Mídias: ensaios sobre Comunicação, Política, Arte e Sociedade no Mundo Contemporâneo (IV COMPÓS, 1996); Mídia e cultura (V COMPÓS, 1997); Comunicação e corporeidades (VIII COMPÓS, 2000); Práticas midiáticas e espaço público, volume 1 (IX COMPÓS, 2001); Interação e sentidos no ciberespaço e na sociedade, volume 2 (IX COMPÓS, 2001). 


\title{
ESTUDOS EM JORNALISMO
}

10.5212/RevistaPautaGeral.v.5.i2.0008

Entre as colaborações para a Compós, destacamos Brasil - comunicação, cultura e política, onde Fausto Neto, além de constar como um dos organizadores, escreve o último capítulo: "A sentença dos media: o discurso antecipatório do impeachment de Collor". Destaca-se por ser análise de notícias relacionadas a outro presidente, embora não relacionado a doenças, como fez anteriormente com Tancredo Neves e faria posteriormente com Lula e Dilma, mas revela a análise político-midiática - algo que Fausto Neto muito bem produziu em sua carreira. Eis o que consta na apresentação do livro:

\begin{abstract}
Racionalidade à parte, os elementos míticos e culturais jamais deixaram de ocupar um espaço importante na experiência política. Por intermédio deles, os grupos políticos legitimam a si mesmos - e muitas vezes as regras do jogo político - através do recurso aos símbolos. Notada especialmente nos regimes autoritários e totalitários, a ritualização da política também se faz presente nos regimes liberal-democráticos, que têm nas eleições o seu rito central. Mais do que meros instrumentos do contrato representativo, as eleições podem ser vistas aí como ritos sazonais de renovação da ordem social, ao mesmo tempo que reafirmam as suas regras fundamentais. A moderna distinção entre o público e o privado, tão desenvolvida pela modernidade e inclusive absorvida por campos com a arquitetura das casas, promiscuamente se mescla na atualidade. Em princípios "lugares públicos", os media invadem os espaços mais privados/íntimos construídos na modernidade, como os quartos. Capturados estes espaços pela expansiva rede de publicização que os media instalam em profusão; eles, oriundos e instalados na esfera pública, são abarrotados com o privado, com a intimidade. Até a política sofre a invasão desenfreada do privado, via media, para legitimar o público. A era Collor, para lembrar algo recente, foi exemplar neste aspecto (FAUSTO NETO et al., 1994).
\end{abstract}

Em uma colaboração entre a Compós e a Editora da UFPB (Edufpb), com organização de Antônio Fausto Neto, é lançado, em 2001, o livro Campo da Comunicação: caracterização, problematizações e perspectivas. Também entre os organizadores estão outros conhecidos pesquisadores brasileiros da área da Comunicação: Gabriel Cohn; José Luiz Braga; L.C. Martino; Maria Imacolata Vassalo Lopes; Muniz Sodré e o antropólogo belga, atualmente professor da Universidade Estadual de Campinas (Unicamp), Etienne Samain. Neste livro, Fausto Neto escreve a apresentação, juntamente com o professor (hoje emérito da UnB), Sergio Dayrell Porto. No texto, se destaca o ponto onde escreve que alguns dos objetivos do livro são: 


\begin{abstract}
d) propor análise entre a interdisciplinaridade e o objeto da comunicação, a partir dos meios, mas ao contrário de um fechamento da problemática, tratar a questão de uma perspectiva que compreenda os meios a partir de uma relação complementar com a cultura de massa, entendida enquanto sentido histórico de uma organização social singular. e) propor uma atualização de categorização do campo da comunicação em sub áreas de conhecimento que contemplem os diferentes percursos e esforços teóricos e metodológicos para pensar os diferentes processos e práticas desenvolvidas no continente do campo das mídias, como possibilidade de produzir, num futuro breve respostas sobre a constituição do campo (FAUSTO NETO, 2001).
\end{abstract}

Tais trechos reforçam a visão abrangente do já vasto campo da comunicação que tinha e ainda tem o autor. O que não o impedia de pensar categorizações, subáreas e dar a devida importância a campos maiores, como o jornalismo. Uma das ações que demonstram tal fato é o retorno de Fausto Neto à UFPB, em 2013, onde, desta vez, ajuda a formar o primeiro mestrado profissional em jornalismo do Brasil. Hoje, ele ainda se mantém como professor colaborador do programa.

A primeira colaboração de Fausto Neto como autor solo pela Edufpb é Desmontagens de sentidos - leituras de discursos midiáticos, de 2001. Originalmente, capítulos deste livro foram textos produzidos para diferentes contextos. São manifestações do autor sobre questões relativas ao processo midiático enquanto práticas sociais e de sentido, especialmente onde os media estiveram não apenas como temática, mas, especialmente, como objeto de reflexões. A pluralidade dos textos reflete a abrangência da pesquisa do autor, com títulos que tratam de televisão, religião, recepção, cidadania e mais uma vez, o cordel.

Ensinando a televisão - Estratégias de Recepção da TV Escola, lançado no mesmo ano de 2001 e também pela Edufpb, estuda o canal TV Escola a partir de uma perspectiva interacional, procurando saber como se constituem, como funcionam e que destinos tomam, enquanto efeitos simbólicos, os vínculos e enquadramentos entre a oferta e a recepção. Segundo o autor, o projeto TV Escola é uma das mais complexas estratégias de "políticas de comunicação" desenvolvida sob uma razoável ação de controle e regulação do Estado. Ele afirma que este projeto não é exclusivamente uma oferta comunicativa contendo uma intencionalidade de governo, ele é o resultado das interações que os dois campos travam simbolicamente, através de rituais estratégicos que 2018. 
se desenvolvem no cenário das circulações dos discursos. A legitimação da TV Escola passaria necessariamente por várias redes sociais, por vezes desconhecidas, onde os indivíduos operariam simbolicamente.

Em 2008, Fausto Neto é mais uma vez organizador de um livro, desta vez, pela editora Paulus, intitulado Midiatização e processos sociais na América Latina, juntamente com os professores Pedro Gilberto Gomes, José Luiz Braga e Jairo Getúlio Ferreira. O tema central da obra é o conceito da midiatização - relevante até hoje nas pesquisas do autor - e a repercussão desta sobre as práticas acadêmicas. O objetivo foi refletir sobre a midiatização enquanto fenômeno que corresponde a dinâmicas amplas, produzidas por processos complexos que incidem sobre a organização e funcionamento da sociedade, em escala mundial.

Interfaces jornalísticas - ambientes, tecnologias e linguagens é outra produção de Antônio Fausto Neto lançada pela Edufpb, em 2011, organizada por ele e pelo professor José David Campos Fernandes. Como o título entrega, a obra é focada no jornalismo e suas interfaces e traz textos de professores da UFPB, em sua maioria, refletindo sobre o campo jornalístico sob diferentes aspectos. No livro, Fausto Neto escreve o primeiro capítulo, "Transformações do jornalismo na sociedade em vias de midiatização", onde reflete sobre as incidências dos processos de midiatização sobre o jornalismo, levando-se em conta efeitos do deslocamento de ênfases da "sociedade dos meios" para a "sociedade midiatizada".

Em 2012, seguindo sua característica de trabalhos em conjunto, Fausto Neto organiza com Jean Mouchon e Eliseo Verón o livro Transformações da midiatização presidencial: corpos, relatos, negociações e resistências uma obra que reúne os trabalhos apresentados e discutidos no colóquio homônimo, realizado na cidade de Japaratinga, Alagoas, entre 21 e 25 de setembro de 2009, organizado pelo Centro Internacional de Semiótica e Comunicação (Ciseco), do qual Fausto Neto é um dos fundadores e atuais diretores. A obra une a sempre interessante temática de mídia e política, com trabalhos envolvendo comunicação, marketing, sociologia, ciências políticas e semiologia, relacionados à midiatização presidencial, tema caro ao pesquisador Fausto Neto.

\section{Fausto Neto e o jornalismo}

Revista Pauta Geral-Estudos em Jornalismo, Ponta Grossa v.5, n.2, p. 132-146, Jul/Dez 2018. 
Pelo menos dois artigos - escolhidos por serem mais recentes e terem sido produzidos em duas das poucas universidades públicas brasileiras com pós-graduação strictu sensu em jornalismo (Universidade Estadual de Ponta Grossa - UEPG e UFPB) mostram como Fausto Neto, mesmo com sua ampla pesquisa, possui extenso conhecimento da área jornalística - tanto do ponto de vista empírico como teórico - e tem dado grande contribuição para as análises teóricas do jornalismo. Os artigos são: Jornalismo: do chão da fábrica aos novos processos de redesenho da profissão na sociedade em vias de midiatização (Âncora - Revista Latino Americana de Jornalismo, João Pessoa); e Do rádio de pilhas ao smartphone: maio de 1968 a junho de 2013 (Revista Pauta Geral - Estudos em Jornalismo, Ponta Grossa). Os artigos são de 2015 e 2016, respectivamente, sendo o primeiro originalmente uma conferência ministrada por Antônio Fausto Neto, por ocasião da aula inaugural do Programa de Pós-graduação em Jornalismo da UFPB.

Já há alguns anos, Fausto Neto tem trabalhado o conceito de midiatização, formulação que ajuda a refletir sobre diversas questões que o jornalismo vem enfrentando. As pesquisas e reflexões do autor oferecem ao campo jornalístico uma aproximação do conceito de midiatização e ajudam a pensar o jornalismo diante de mudanças que vão da produção ao consumo de notícias. Captar o que está acontecendo e conceituar o jornalismo que ganha novos contornos, dimensões, características diante das transformações da tecnologia nas últimas décadas - e acentuadas nos últimos anos são desafios para os pesquisadores, na compreensão do autor.

Fausto Neto afirma que problemas suscitados pelo desenvolvimento da midiatização vêm sendo escrutinados em estudos latino-americanos e o pesquisador, na realidade brasileira, vem se ocupando em examinar as transformações de práticas discursivas em diferentes campos - política, educação, religião, saúde - a partir de apropriação de características midiáticas (FAUSTO NETO, 2008, p. 120). Seu entendimento do conceito de midiatização é de natureza processual e histórica.

No momento em que os fenômenos de sentido são exteriorizados através de materialidades mecânicas, instaura-se um processo de midiatização. 
É preciso entender que a midiatização é um processo longo, tem várias etapas, mas o que nos interessa como objeto de estudo diz respeito a fenômenos mais recentes relacionados com $\mathrm{O}$ aparecimento de processos midiáticos, em caráter industrial, digamos assim. (...) A midiatização significa $\circ$ desenvolvimento célere de tecnologias convertidas em meios, segundo práticas de produção e de recepção de mensagens, afetando todas as práticas sociais, ainda que de modo diverso (MOLLETA; FAUSTO NETO, 2016, p. 129-130).

Ao comentar sobre pós-internet, Fausto Neto rejeita o conceito, pois, segundo o autor, é difícil ir além de especulações.

Eu acho que tem um discurso muito vazio sobre isso e muito apologético, como se a internet fosse uma estrutura lisa, sem percalços, como se a própria dinâmica social não repercutisse sobre ela. Pelo contrário, a internet vira agora um campo, onde vai se dar a batalha campal da disputa de sentidos, com deslocamentos que os campos sociais fazem para lá de suas práticas. Então, é preciso qualificar esta discussão, no sentido que o modo de existência das técnicas não opera de modo automático, os processos de legitimação das técnicas decorrem de embates que ocorrem no interior das práticas dos campos sociais (idem, p. 130).

Sobre se as tecnologias contemporâneas facilitam o acesso às fontes, Fausto Neto avalia:

(...) os acontecimentos passam em situações muito distintas daquilo que nós descrevíamos no final de décadas passadas. O que isso tem a ver com o jornalismo? De um lado, assim como nós, os jornalistas, os comunicadores, estamos acossados por esta mutação e, como eu dizia, com todas estas práticas sociais acossadas por estas mutações também, significa dizer que, as nossas fontes lidam em termos de lógicas, com os mesmos problemas que os jornalistas enfrentam do ponto de vista da compreensão do que seja noticiabilidade hoje. Manejam equipamentos, editam (idem, p. 133).

E como já discutia, décadas atrás, no livro Corpo falado (1988), sobre as condições de trabalho dos jornalistas, o autor, mesmo após anos de pesquisa e docência, não se desconectou do mundo profissional dos jornalistas: 


\section{ESTUDOS EM JORNALISMO}

10.5212/RevistaPautaGeral.v.5.i2.0008

Para exemplificar a transformação do acontecimento, os jornalistas estão vivendo uma mutação muito grande, enfrentando cenários complexos porque alguma coisa que passava por esse poder de referenciar o mundo, nomear, ler, classificar, de fato não está mais somente na mão desse campo e dos seus profissionais, e está na mão da sociedade (idem, p. 133-134).

Ao mesmo tempo que entende o drama da mudança dos acontecimentos, reconhece a importância do jornalismo:

Quer dizer, os acontecimentos estão organizados segundo metodologias para as quais nós não estamos preparados metodologicamente para descrevê-las, para apreendê-las. As nossas metodologias, ainda que de alta performance, apurar, ouvir, escrever, fotografar, filmar, tudo isso, reúne operações que não davam conta desse funcionamento de aglomerações momentâneas, que talvez tivessem parte do domínio destas tecnologias, mas de uma grande dimensão dos problemas, talvez em termos. É um processo experimental emergente ali. Mas como a mídia não poderia jamais perder esse lugar de narração, de nomeação, e de referenciar o mundo, o que é que ele faz? (idem, p. 134).

E aconselha aos estudantes e pesquisadores a ir ao encontro de referências tradicionais e ver o que ainda serve ao campo ao analisar tecnologias e meios contemporâneos.

Nós temos que estudar o acontecimento hoje com outras ferramentas e fundamentos. Temos que abrir os manuais de redação, os textos de Teorias da Notícia, e discutir o que ainda prevalece como aconselhamentos úteis para nossa formação. É preciso observar empiricamente estas coisas que estão acontecendo e estão muito perto do nosso mundo. (...) Agora, o grande problema, nesse contexto no qual as mídias tradicionais perdem ou podem perder o protagonismo, envolve: quais os passos que elas darão no sentido de terem consigo a lealdade e a fidelização do leitor. Esse é um desafio que repercute sobre o negócio da comunicação, sobre os ideais de uma organização, suas metas políticas, etc. (...) A midiatização é esse fenômeno complexo, porque ele é incompleto. É a processualidade. Não é um problema de um mundo de especialistas, dos jornalistas, é um problema de sociedade. A midiatização é uma questão de sociedade. Tudo isso vai colocar pautas para a gente discutir (idem, 136-137). 
Na conferência em forma de diálogo proferida em 2015 na UFPB e transcrita pela Revista Âncora, Fausto Neto discorreu sobre os desafios que afetam o mercado de trabalho dos jornalistas, pesquisas do campo e refletiu sobre o paradigma da sociedade em vias de midiatização. O pesquisador elencou algumas questões tidas como problemas centrais das instituições preocupadas com a formação dos jornalistas e com o funcionamento dessa profissão, a saber: o futuro do jornalismo com a emergência dessas tecnologias que invadem o tecido social; haverá outras possibilidades de codificação de realidade, sobretudo com a emergência dos chamados amadores?; a profissão jornalística terá um futuro formalmente reconhecido diante de tudo que cerca a sua existência e a sua identidade?; qual é o futuro do jornal impresso?; o jornal impresso tem os dias contados?; o que é o jornalismo hoje, no contexto da internet?, entre outras reflexões a respeito da identidade do jornalista, fronteiras internas e lutas do campo.

\begin{abstract}
Neste novo contexto o acontecimento deixa de ser acolhido por um chão de fábrica, denso, plural, com uma hierarquia sob tensão e sob acordos momentâneos, uma sinfonia problemática, podemos dizer. $\mathrm{O}$ acontecimento deixa de ser acolhido por esse chão de fábrica, e passa a ser monitorado por um outro desenho de divisão social do trabalho, sobre o qual aparecem muitas variáveis como o da terceirização de atores no âmbito do ofício, a emergência dos administradores de conteúdos, em suma um redesenho que ressignifica a própria natureza da profissão. Esse registro suscita um debate muito importante (FAUSTO NETO, 2015, p. 177).
\end{abstract}

\title{
Produtividade e aperfeiçoamento contínuos
}

Além dos estudos de graduação e pós-graduação realizados em instituições do Brasil e na França, Fausto Neto realizou, na década de 1970, especialização em Comunicação Coletiva no Equador. Além do doutorado, seus estudos na França incluem especializações em Estudos Aprofundados de Semiologia das Artes e Literatura; e Estudos de Desenvolvimento. Extensivo a suas atividades acadêmicas, foi secretáriogeral da antiga Associação Brasileira das Emissoras Públicas, Educativas e Culturais (Abepec) e um dos fundadores. Foi ou é consultor de várias instituições públicas de pesquisa e de capacitação de recursos humanos, como a Coordenação de 
Aperfeiçoamento de Pessoal de Nível Superior (Capes); Conselho Nacional de Desenvolvimento Científico e Tecnológico (CNPq, Fundação de Amparo à Pesquisa do Estado de São Paulo (Fapesp); Fundação Osvaldo Cruz; Fundação de Apoio à Pesquisa do Estado de Pernambuco; bem como é membro de conselhos editoriais de diversas publicações científicas nacionais.

Se traçarmos uma linha cronológica resumida, podemos afirmar que os estudos e pesquisa de Fausto Neto no início de sua carreira concentraram-se em semiologia e análise do discurso, abrangendo análise ideológica e metodologia do discurso informativo. Em seguida, suas pesquisas abrangem o jornalismo e objetos midiáticos, envolvendo ou não política, como a midiatização de doenças e presidentes. Pesquisas nessa temática abarcaram estratégias de noticiabilidade. Por um tempo, suas pesquisas circundaram estudos televisivos, análise religiosa e migração, bem como interessantes reflexões em diversos temas caros ao jornalismo, como crítica, ombudsman, internet, identidade, rotinas, entre outros. Nos últimos anos, seu enfoque tem se voltado para os estudos da midiatização, sob diversos prismas, a saber: dimensões teóricas e socioeconômicas do processo de midiatização social; midiatização discurso científico; midiatização das práticas sociais; afetações da midiatização sobre o ofício jornalístico; e gênese, funcionamento e complexificação das zonas de contato na sociedade em midiatização, além de uma pesquisa mais recente sobre comunicação e a área de saúde, envolvendo estratégias, relações públicas e atenção básica.

Sua vinculação com a saúde não é recente. Para além das temáticas envolvendo doenças, Fausto Neto foi consultor da Associação Brasileira de Saúde Coletiva (Abrasco) e do Ministério da Saúde. Como mencionado, seus conhecimentos são incorporados em suas pesquisas, nunca abandonados e seus percursos possuem consistência e coerência. Para resumir estas informações, exemplos estão nas suas produções dos últimos anos. Uma vez que já mencionamos os livros, artigos científicos recentes analisam temas como o impeachment da ex-presidente Dilma Rousseff; análise televisiva das manifestações brasileiras de 2013; epistemologia, jornalismo e midiatização; e a morte de Hugo Chávez, ex-presidente da Venezuela.

O corpo de pesquisa e obras de Antônio Fausto Neto são compostos de dezenas de livros e mais de uma centena de artigos, sem falar nas já citadas inúmeras 
cooperações, eventos, ensaios e grupos de pesquisa. Foram aprendizados, pesquisa e colaborações nacionais e internacionais, que deram origem a toda essa gama de produção, parcialmente aqui apresentada. Este conjunto de saberes revela para os estudiosos do jornalismo um apanhado epistemológico de grande valia para entender as transformações da área da comunicação, ter uma melhor compreensão do que foi o jornalismo brasileiro, suas metamorfoses e desafios atuais. Fausto Neto possui um legado por trás de si e pela frente, pois, como dito, segue produtivo. Jornalismo e ciência agradecem.

\section{Referências}

FAUSTO NETO, Antônio. Chávez, morte e desamparo informativo na cena da circulação midiatizada. Rizoma, v. 1, p. 25-45, 2013.

Hacker, 1999.

Comunicação e mídia impressa: estudo sobre a AIDS. São Paulo: Cordel e a ideologia da punição. Petrópolis: Vozes, 1979.

O corpo falado: a doença e morte de Tancredo Neves nas revistas semanais brasileiras. João Pessoa: UFPB/PROED-MEC, 1988.

O corpo falado - doença e morte de Tancredo Neves nas revistas semanais brasileiras. 2. ed. Belo Horizonte: PUC-MG, FUMARC, 1989.

Desmontagens de Sentidos: Leituras de discursos midiáticos. João Pessoa: UFPB/Editora Universitária, 2001.

Dos circuitos à sentença: $O$ impeachment de Dilma Rousseff no ambiente da circulação midiatizada. InMediaciones de la Comunicación, v. 11, p. 97-111, 2016.

Ensinando à televisão: estratégias de recepção da TV escola. João Pessoa: Ed. Universitária, 2001.

Jornalismo: do chão da fábrica aos novos processos de redesenho da profissão na sociedade em vias de midiatização. Âncora Revista Latino-americana de Jornalismo, João Pessoa, p. 155 - 169, 17 jun. 2015.

Portugal, v. 5, p. 41-53, 2005.

O jornalismo e os limites da representação. Caleidoscópio (Lisboa), $110-125,2009$. Jornalismo: sensibilidade e complexidade. Galáxia (PUCSP), v. 9, p.

35-47, 2008.

Ombusdman: A interrupção de uma fala transversal. InTexto, v. 1, p. 2001.

Práticas midiáticas e espaço público. Porto Alegre: EDIPUCRS,

Mortes em derrapagem: os casos Cazuza e Corona no discurso da comunicação em massa. Rio de Janeiro: Rio Fundo Ed., 1991.

Tchau, querida: Leitura do impeachment-revista. Animus (Santa Maria. Online), v. 15, p. 62-81, 2016. 
FAUSTO NETO, Antônio et al. (Org). Brasil: comunicação cultura \& política. Rio de Janeiro: Diadorim, 1994.

FAUSTO NETO, Antônio et al. (Org). Interação e sentidos no ciberespaço e na sociedade. Porto Alegre: EDIPUCRS, 2001.

FAUSTO NETO, Antônio et al. (Org). Midiatização e processos sociais na América Latina. São Paulo: Paulus, 2008.

FAUSTO NETO, Antônio; FERNANDES, José David Campos. Interfaces Jornalísticas: ambientes, tecnologias e linguagens. João Pessoa: Editora da UFPB, 2011.

FAUSTO NETO, Antônio; HOHLFELDT, Antônio. Comunicação e corporeidades. João Pessoa: Ed. Universitária, 2000.

FAUSTO NETO, Antônio; PINTO, Milton José. 0 indivíduo e as mídias: ensaios sobre comunicação, política, arte e sociedade no mundo contemporâneo. Rio de Janeiro: Diadorim, 1996.

FAUSTO NETO, Antônio; PRADO, José Luiz Aidar; PORTO, Sérgio Dayrrel. Campo da Comunicação: caracterização, problematizações e perspectivas. João Pessoa: Editora Universitária/UFPB, 2001.

FAUSTO NETO, Antônio; MOUCHON, Jean.; VERON, Eliseo. (Org.). Transformações da midiatização presidencial: corpos, relatos, negociações, resistências. 1.ed. São Paulo: Difusão Editora, 2012.

FAUSTO NETO, Antônio; WESCHENFELDER, Aline. A enfermidade de Lula: enunciando a corporeidade do acontecimento. RECIIS. Revista Eletrônica de Comunicação, Informação \& Inovação em Saúde (Edição em Português. Online), v. 6, p. 10.3395/reciis., 2012.

MOLLETA, Cléber; FAUSTO NETO, Antônio. Do rádio de pilhas ao smartphone: maio de 1969 a junho de 2013 (Entrevista). Revista Pauta Geral - Estudos em Jornalismo, Ponta Grossa, vol.3, n.1 p. 128-137, Jan/Jun, 2016.

Recebido em: 11/06/2018

Publicado em: 21/12/2018 